\title{
Cuesta, Virginia (2012). Historia, Narrativa y Enseñanza. Cinco estudios de casos, Saarbrücken: Editorial Académica Española, 90 páginas por Yesica Martín
}

Universidad Nacional de La Plata

martin_yesica@yahoo.com.ar

Se ha debatido mucho acerca de la narración y la narrativización en la historiografía académica. En este sentido, también se produjeron aportes interesantes sobre la temática desde la filosofía de la Historia que problematizan sobre la manera de relatar los hechos históricos, y la relación estrecha entre literatura y la ciencia histórica. ${ }^{1}$ Cómo afirma Hayden White «la narrativa es un metacódigo, un universal humano sobre cuya base pueden transmitirse mensajes transculturales acerca de la naturaleza de una realidad común» (White, 1992:17).

Al respecto, el libro de Virginia Cuesta, además de realizar un breve análisis de los principales debates historiográficos en torno a la narración y su relación con la Historia, nos ofrece una mirada interesante ya que traslada estas cuestiones a la práctica docente en el aula.

La autora en cuestión parte de algunos interrogantes que han guiado su investigación y que han surgido de su propio recorrido como docente. A saber:

¿Cómo leen los textos escolares o científicos, las fuentes primarias y/o secundarias, los sujetos que no tienen formación disciplinar universitaria?¿Qué procedimientos efectivos realizan los docentes para enseñar a escribir textos que fijen la atención en el devenir histórico-social? (...) icuál es la importancia que asumen las narraciones o ficciones históricas producidas por los alumnos a la hora de aprender y enseñar Historia en el aula? (...) icuál es el impacto de la vinculación entre el discurso literario y el histórico tanto para la enseñanza de la Historia como de la Literatura? (Cuesta, 2012:6).
Desde una perspectiva multidisciplinar, integrando aspectos propios de la Crítica Literaria, la Historia de la Lectura, los estudios sobre la narrativa, la Sociología de la Cultura y la Etnografía se intenta dar respuesta a los interrogantes arriba mencionados. La autora analiza tres objetos de estudio concernientes a las prácticas de lectura y escritura. Por un lado, se centra en la práctica de la escritura de textos de ficción histórica estimulando la imaginación y empatía de los alumnos de la Escuela Secundaria Básica. Por otro lado, estudia las formas y la manera en que tanto los alumnos como los docentes realizan lecturas sobre textos de Ciencias Sociales. Y para finalizar, expone de manera enriquecedora el uso de la Literatura para la enseńanza de la Historia y de la Historia para la enseñanza de la Literatura.

Los estudios de campo fueron realizados por la autora entre los años 2002 y 2004 en diferentes cursos de Escuelas Secundarias Básicas ubicadas en el partido de La Plata y de General San Martín, provincia de Buenos Aires. Virginia Cuesta nos introduce en las distintas realidades de las escuelas donde realiza sus investigaciones, contándonos la Historia de las mismas, y el contexto socioeconómico en la que están insertas. En este sentido, la autora hace hincapié en poner en tensión los discursos hegemónicos acerca de la exclusión y marginalidad de los sectores más humildes en el ámbito educativo. 
En el caso del primer objeto de estudio, la autora en cuestión explica con ejemplos prácticos cómo se puede desplegar la imaginación y la empatía en las clases de Historia y Ciencias Sociales. Cuesta parte del siguiente interrogante: «¡es posible propiciar el desarrollo del pensamiento narrativo a través de actividades de escritura en las cuales los alumnos puedan recrear el pasado histórico utilizando la ficción y apropiarse de ese 'otro' posible mundo que ya no existe pero que de algún modo pervive?» (Cuesta, 2012:33). En este sentido, revisita distintos ejercicios que pueden ser de tipo descriptivo (trasladando al alumno hacia el pasado) o empatéticos (a través de juegos de simulación o diferencias entre el pasado y el presente). Deben realizar actividades referidas a la lectura y escritura, y la autora analiza los resultados en clave de crítica literaria. En las narraciones producidas se perciben tanto las categorías trabajadas previamente en clase como también conceptos y saberes extraídos de otros contextos como por ejemplo el cine, la literatura o la televisión.

La autora nos plantea cuestiones que son recurrentes en las narraciones producidas en las clases, como por ejemplo un espacio temporal y geográfico difuso, identificaciones personales y el uso de la primera persona, la constante utilización de los finales felices, dificultad para comprender los valores pertenecientes a otras culturas, entre otras temáticas.

En el Segundo Caso presentado se trabaja con alumnos de la periferia del Gran La Plata, en un contexto socioeconómico más vulnerable que en el caso anterior. En este sentido, se ocupa de cuestionar las concepciones hegemónicas acerca de que los alumnos de menos recursos económicos presentan mayores dificultades a la hora de imaginar situaciones históricas, como también la idea de que poseen un lenguaje «pobre». Aquí se analiza la espontaneidad que aparece en la escritura narrativa por parte de los alumnos, apoyándose en autores como Jerome Bruner o Kieran Egan, quienes afirman que la narratividad forma parte de nuestra cultura y de nuestra manera de ver y comprender el mundo. Además, en este apartado observa la forma en que los adolescentes entienden las consignas propuestas. Presenta un ejemplo de una alumna que, si bien comprende lo pedido por la docente del curso, a la hora de narrar recurre a elementos fantásticos generando, de esta manera, otra arista que complejiza y enriquece la actividad.

Pasando al Tercer Caso, la autora aborda las distintas teorías acerca de la lectura como una "práctica social» siguiendo los aportes de Roger Chartier, Michele Petit y Elsie Rockwell. Desentraña la idea de que la lectura y la escritura son prácticas arraigadas desde la escuela primaria, y por tanto naturalizadas por parte de los alumnos, como consideran los docentes de tradición positivista. Afirma que la lectura es una práctica cultural y compleja que debe asirse en su historicidad. Además, como dice Rockwell: «en el contexto del aula, esta relación (con el texto escrito) es mediada por la continua interacción oral de los maestros y los alumnos, quienes construyen distintas formas de apropiarse de la lengua escrita y de abordar la lectura de un texto» (Rockwell, 1995:198).

En los ejemplos proporcionados por Virginia Cuesta se pueden observar las distintas maneras de «leer» los textos propuestos por la docente. En esta oportunidad, se presentan textos relacionados con la conquista y colonización de América, que son leídos y explicados por la profesora a cargo, y a continuación se les solicita a los alumnos la realización de un resumen de los mismos. Ante esta consigna se percibe la apropiación de los contenidos por 
parte de los alumnos, y las distintas consideraciones de lo que para cada uno significa un resumen.

En el Cuarto Caso se analizan dos cuestiones desde el punto de vista teórico. La primera de ellas se refiere al tratamiento del pasado reciente en el aula. En este aspecto, la autora sintetiza de manera breve los principales debates que se producen al respecto, detallando la diversidad de fuentes, las subjetividades que provoca el abordaje de la Historia reciente, la relación existente entre Historia y memoria, el tratamiento de hechos traumáticos para la sociedad, los problemas de periodización, entre otras problemáticas. En segundo lugar, plantea la riqueza que genera el uso de la literatura en las clases de Historia. Expone, mediante los argumentos de un fragmento de la investigación de Petit, cómo un texto literario puede generar una mirada más cercana a la vida de aquellas personas anónimas que fueron atravesadas por distintos momentos históricos. También, siguiendo a Beatriz Sarlo, la autora presenta las maneras posibles en que puede utilizarse la literatura desde una perspectiva histórica. De esta manera nos abre la posibilidad de pensar diferentes aristas y entrecruzamientos que posibiliten un enriquecimiento en las prácticas docentes.

Luego de realizar esos recorridos teóricos se adentra en la experiencia como docente en una escuela de la localidad de Gonnet, donde debía dictar sus clases sobre Historia reciente. En esta oportunidad decidió utilizar textos literarios. Para trabajar el período que abarca desde 1955 y 1976 en Argentina eligió fragmentos de la novela Recuerdo de la Muerte de Miguel Bonasso. La utilización de este recurso motivó a los alumnos a indagar sobre el contexto histórico de la época, preguntando no sólo sobre otros aspectos de la novela, sino también sobre el surgimiento de las distintas agrupaciones armadas. En el momento de analizar los últimos años de la dictadura militar se valió de un cuento llamado «La larga risa de todos estos años» de Rodolfo Fogwill. A partir de la lectura de estos textos literarios, que complementaban los textos de carácter historiográficos se pudo ampliar la mirada sobre los acontecimientos pasados.

En los últimos casos se presentan ejemplos de jóvenes que leen asiduamente literatura. Las experiencias que se comentan aquí tuvieron lugar en el curso de Articulación del Nivel Polimodal/Escuela Media para la Educación Superior dictado en la localidad de San Martín. En esta oportunidad se trabajaron textos literarios escritos en el siglo XIX, como por ejemplo "Así» de Eduardo Wilde y «Los Mc Williams y la alarma para ladrones» y "La Historia del inválido» de Mark Twain. En estas prácticas se trabaja en torno al realismo en la literatura y las categorías de verosimilitud e inverosimilitud presentes en cada lectura.

Por último, en las conclusiones, la autora vislumbra las relaciones entre los primeros casos en los que se realizaron actividades de carácter empático. Aquí concluye que se ha podido observar la manera en que los alumnos aprenden los contenidos disciplinares y la forma en que los alumnos se introducen en el pasado. Estas consignas juegan entre la macro y la microHistoria; además estas prácticas pueden habilitar espacios que reafirmen la identidad individual y ocasionen referencias autobiográficas por parte de los alumnos.

Cuesta considera que estos enfoques de la práctica docente pueden generar una buena recepción por parte de los alumnos, promoviendo conocimientos a través no sólo de la narración sino también desde lo lúdico. Otro punto que analiza en las conclusiones se refiere 
a las diversas formas de lecturas, las imágenes, las escrituras, los estados de los textos, la relación entre ellos y el mediador de la lectura (que puede ser el docente) y las distintas maneras de apropiación de los contenidos. Finalizando, la autora propone una interrelación estrecha entre literatura e Historia, y deja abierta la posibilidad de un estudio a la inversa, es decir, explicar a la disciplina literaria desde un punto de vista histórico. Al final del libro nos encontramos con un anexo, donde aparecen todos los trabajos de los alumnos expuestos en el recorrido del texto, posibilitando un acercamiento a la actividad de campo realizada por la investigadora.

El libro nos introduce en varios debates teóricos, que si bien algunos son sólo mencionados, invitan al lector a interiorizarse sobre distintas temáticas. Por otro lado, se estima que el libro realiza un gran aporte a las prácticas docentes, ya que nos brinda la posibilidad de pensar propuestas didácticas con ejemplos concretos.

\section{Notas}

${ }^{1}$ Aportes interesantes al respecto se pueden encontrar en Danto (1996), Ricoeur (1989) y White (1992), entre otros.

\section{Referencias bibliográficas}

Danto, A. (1996). Historia y narración. Barcelona: Paidós. Ricoeur, P. (1989). Tiempo y narración. México: Siglo XXI. Rockwell, E. (Coord.) (1995). En torno al texto: tradiciones, docentes y prácticas cotidianas en: La escuela cotidiana. México: Fondo de Cultura Económica.

White, H. (1992). El valor de la narrativa en la representación de la realidad en: El contenido de la forma. Narrativa, discurso y representación histórica. Barcelona: Paidós. 